\title{
Margens de sentido(s) nas águas textuais e discursivas
}

\section{Borders of meaning(s) in textual and discursive waters}

\begin{abstract}
Carteiros do texto, viajamos de uma margem à outra do espaço do sentido valendo-nos de um sistema de endereçamento e de indicações que o autor, o editor e o tipógrafo balizaram.
\end{abstract}

(Pierre Levy, 1996)

\section{Resumo}

O presente artigo traz uma reflexão sobre margens de sentido textuais e discursivas com o objetivo de desvelar caminhos que existem entre significados textuais e discursivos, bem como entre textualidade e níveis de leitura. Para tanto, busca-se apoio teórico nos estudos de natureza filosófica, na esteira do pensamento de Paul Ricouer (1984), passando pela Linguística Textual (Koch, 1997; Beaugrande e Dressler, 1981; Guimarães, 2009 e Marcuschi, 2008 entre outros), até chegar aos níveis de leitura propostos por Adler e Doren (1974), enfocados em termos de significados e significações (Freire, 1981; Eco, 1986; Carraher, 1987 e Silva, 1997, 2012). Os primeiros resultados podem significar uma pequena contribuição para todos aqueles/as que trabalham com textos, níveis de leitura, significados linguístico-discursivos, enfim, com a linguagem como prática social.

Palavras-chave: Texto. Textualidade. Níveis de leitura. Sentido(s). Palavra. Discurso.

\begin{abstract}
This paper is about discursive and textual meanings, as well as textuality and reading levels. Therefore, it seeks to support theoretical studies of a philosophical nature, thought of Paul Ricoeur (1984), through Textual Linguistics (Koch, 1997; Beaugrande and Dressler, 1981; Guimarães, 2009 and Marcuschi, 2008 among others), until reaching the reading levels proposed by Adler and Doren (1974), focused in terms of meanings and significances (Freire, 1981; Eco, 1986; Carraher, 1987, and Silva, 1997, 2012). The first results can mean a contribution for all those who work with texts, reading levels, linguistic-discursive meanings and language as a social practice.
\end{abstract}

Key words: Text. Textuality. Reading levels. Meaning(s). Word. Discourse. \footnotetext{
pesquisadora colaboradora plena junto ao Programa de Pós-Graduação em Linguística da
Universidade de Brasília (PPGL/UnB), líder do grama de Pós-Graduação em Linguística da
Universidade de Brasília (PPGL/UnB), líder do Grupo Brasileiro de Estudos de Discurso, Pobreza e Identidades ( $\mathrm{CNPq}$ ) e vice-presidente da Associação Latinoamericana de Estudos do Discurso (ALED).

Doutora em Linguística Hispânica pela Universidade Nacional Autônoma do México
(UNAM), com Pós-Doutorado em Análise de Discurso Crítica (ADC) e Linguística Sistêmico-Funcional (LSF) pela Faculdade de Letras da Graduação em Letras, Português-Inglês, pelo Centro de Ensino Unificado de Brasília (UniCEUB) e Mestrado em Linguística pela Universidade de Brasília (UnB), onde atua como
} 


\section{Introdução}

O objetivo deste artigo é traçar uma espécie de cartografia ampliada da noção de texto com vistas a contribuir para o alcance de sentido(s), disposto(s) às margens das águas textuais e discursivas, balizadas pela palavra falada, escrita e/ou ouvida. Trata-se, aqui, de uma proposta de viagem que prevê uma trilogia de ações, o que permite vislumbrar um apoio pertinente à égide da leitura, uma vez que esta envolve três lados de um signo linguístico: a palavra. Pode-se postular que uma ação pedagógica de leitura costuma envolver três movimentos de um único elemento: a palavra falada (discurso), a palavra escrita (literatura) e a palavra ouvida (educação), conforme já sugeri em Silva (2008). ${ }^{1}$ Em termos etimológicos, enquanto educação envolve a ação de criar ou nutrir, pode-se associar literatura com a arte de trabalhar bem as palavras na arquitetura de um dado texto, enquanto produto, que envolve um processo discursivo.

A propósito, etimologicamente, discurso abarca a ideia de movimento para diversos lados (dis+cursu). Pode-se considerar que todo texto, na condição de unidade do discurso, pressupõe uma relação dialógica que se constitui pelo fluxo da (re)ação de interlocutores, o que envolve autores e leitores passando, é claro, por editores e tipógrafos, conforme bem observa Pierre Levy na epígrafe acima.

O artigo encontra-se dividido em seis seções, incluindo esta introdução. Na segunda, apresento o conceito de texto e proponho considerá-lo também como um objeto virtual. Na terceira, mediante a apresentação dos requisitos da textualidade, reforço o passaporte teórico que ancora a revisão alcançada. A quarta seção é dedicada a procedimentos metodológicos concernentes a três níveis de leitura, balizados pelas margens de sentido(s) do discurso materializado em texto. A quinta seção sugere um momento empírico de leitura ativa. Nas considerações finais, arremato, com o leitor, resultados da viagem sugerida.

\section{Ampliação das margens da noção de texto}

Desde uma margem de sentido corrente na linguística textual, pode-se reconhecer que um texto equivale a uma trama de frases formadas por palavras ou por expressões que costumam aparecer enlaçadas por uma conectividade sequencial (coesão) ou cingidas, pelo menos, por uma conectividade semântica (coerência). Trata-se de um conceito pertinente à associação metafórica de texto a "tecido". Daí a etimologia do vocábulo 'texto. Já desde uma margem de natureza filosófica, na esteira do pensamento de Paul Ricoeur (1984), pode-se conceber o texto como a semantização da linguagem pela palavra, ou melhor, pelo discurso. Em ambas as acepções, a ideia de texto como manifestação verbal de conteúdo semântico está implícita.

Observa Ingedore Koch (1997) que, dependendo da orientação teórica que se adote, um mesmo objeto pode ser compreendido de diferentes maneiras e que o conceito de texto não foge à regra. Depois de revisar a literatura linguística pertinente à trajetória de diversas concepções de texto, desde suas origens na linguística textual, passando por orientações de natureza pragmática, até as que consideram o texto como processo, ressalta a referida autora que a propriedade definidora do texto tem a ver com uma complexa rede de fatores de ordem situacional, cognitiva, sociocultural e interacional. De acordo com Koch (2002, p. 154), um texto é um evento comunicativo no qual se cruzam ações linguísticas, cognitivas e sociais.

Neste estudo, procuro também apontar o texto como um objeto virtual, passível de ser navegado, e a leitura como um processo de atualização do mesmo. A propósito, desde suas origens mesopotâmicas, o texto já podia ser considerado como objeto virtual, abstrato, independente de um suporte específico. Sugere Pierre Levy (1996) que um texto virtual pode-se atualizar em múltiplas versões, traduções, edições, exemplares e cópias. Vale a pena associar as ideias de Levy com a proposta de Umberto Eco (1986, p. 35), para quem um texto "representa uma cadeia de artifícios de expressão que devem ser atualizados pelo destinatário". Quanto à ideia de atualização, Eco argumenta que um texto é incompleto por duas razões. Por um lado, porque qualquer texto escrito, frases ou termos isolados exige habilidades do leitor. Por outro lado, porque um texto é sempre entremeado de "nãoditos", ou seja, cheio de espaços em branco para serem preenchidos por interlocutores. 
Mas resulta que a linguagem verbal é linear no espaço (modalidade escrita) e linear no tempo (modalidade oral). Nessa perspectiva, enquanto nas entrelinhas de um texto escrito encontram-se os espaços em branco, podemos sugerir que nas fronteiras de um texto falado encontramos espaços de silêncio, demarcados nas pausas. Nas entrelinhas, ou nas fronteiras, de um texto encontram-se, pois, inúmeros espaços, prontos para serem preenchidos por aquele leitor/ouvinte que, na condição de "carteiro-viajante", estiver disposto a assumir o seu verdadeiro papel de interlocutor ao navegar rio abaixo (ou rio acima) nas águas de sentido(s) de um discurso materializado em texto.

Não se trata de uma viagem relaxada, já que se há de levar em conta todas as conexões possíveis na superfície das águas textuais, que funcionam como pistas referenciais, ou como uma espécie de âncoras, inclusive de natureza semântica e pragmática, dispostas nas margens de sentido(s) de um texto/discurso. Trata-se de uma busca de modos de processamento que conduzem a pistas de um processo (discurso), balizadas às margens de um produto (texto), o que será tratado a seguir.

\section{Os requisitos da textualidade}

Cabe, aqui, mencionar que essa viagem requer conhecimento de uma série de requisitos que uma manifestação linguística humana deve possuir para se configurar como texto. Trata-se da denominada 'textualidade', categoria que, na proposta de Halliday \& Hasan (1976), bem como na de Beaugrande e Dressler (1981), equivale a um conjunto de propriedades que dão 'tessitura' a qualquer texto. Ao discutir a textualidade, a linguista brasileira Elisa Guimarães (2009) comenta o seguinte:

\begin{abstract}
Obras clássicas no campo da Linguística Textual focalizam não o texto (produto), mas a forma de enunciação textual (processo), concebendo, pois, a textualidade como modo de processamento e não conjunto de propriedades inerentes ao texto reduzido a sua dimensão de produto (GUIMARÃES, 2009, p. 12).
\end{abstract}

É justamente com enfoque no processamento que, a exemplo de Guimarães (2009), inscrevemo-nos na perspectiva mencionada acima. Um texto é um evento comunicativo e, ao mesmo tempo, um instrumento de interação que costuma envolver sete dimensões constitutivas: coesão, coerência, intencionalidade, aceitabilidade, situacionalidade, informatividade e intertextualidade.
Trata-se de um elenco de princípios, ou uma espécie de normas de boa formação, que um texto deve possuir para ser considerado como tal (BEAUGRANDE; DRESSLER, 1981; KOCH; TRAVAGLIA, 1989). Consideremos, ainda que de maneira sucinta, os modos de processamento associados a cada um dos princípios mencionados:

coesão - dimensão que caracteriza a maneira pela qual os elementos da superfície textual (segmentos linguísticos) se conectam mutuamente em uma sequência;

coerência - dimensão que concerne à maneira pela qual os componentes do mundo textual (palavras e orações, conceitos e relações subjacentes à estrutura textual) compõem um todo significativo, com uma situação de interlocução mantida pela constância de sentido(s);

intencionalidade - designa a propriedade que concerne às atitudes do locutor, qual seja, a intenção de que a mensagem tenha comunicabilidade, possa impressionar e, em condições contextuais propícias, até mesmo convencer (pela razão) ou persuadir (pela emoção) o interlocutor;

aceitabilidade - concerne à atitude de reconhecimento do interlocutor mediante a qual uma determinada configuração de segmentos linguístico-discursivos pode ser considerada coesa e coerente;

situacionalidade - tem a ver com fatores ou normas sociais que fazem com que um texto seja relevante para uma determinada situação, o que o torna apropriado ou adequado;

informatividade - trata-se do princípio que transparece em que medida as informações veiculadas num texto são esperadas ou não, previsíveis ou imprevisíveis, o que envolve o seguinte parâmetro: quanto maior a previsibilidade de um texto, menor será o seu grau de informatividade e vice-versa;

intertextualidade - característica que pode ser vista a partir de dois prismas: enquanto, por um lado, tem-se a relação de um texto com outros textos nos quais ele nasce e para os quais ele aponta, por outro lado, existe sempre a possibilidade de o relacionar com suas paráfrases, já que é possível encontrar num texto um conjunto de textos possíveis.

Ao atuarem juntos, esses princípios (ou normas) favorecem a textualidade. De acordo com Guimarães (2009, p. 24), "as normas de textualidade mais óbvias são a 
coesão, que se manifesta na superfície textual, e a coerência que subjaz no interior do texto". ${ }^{2}$ Mas cabe, aqui, registrar o pensamento de Marcuschi (2008, p. 122), para quem

\begin{abstract}
"a coerência é um aspecto fundante da textualidade e não resultante dela. É assim que a coerência está muito mais na mente do leitor e no ponto de vista do receptor do texto que no interior das formas textuais".
\end{abstract}

Dois aspectos merecem ser destacados, ainda, para a compreensão de texto e textualidade. Por um lado, as propriedades elencadas anteriormente confirmam que o texto é lugar e representação física da linguagem, espaço de interação, horizonte de significação e, sobretudo, de “jogos de sentidos" conforme sugere Eni Orlandi (1996).

Por outro lado, um texto em si não passa de uma virtualidade, de uma peça com um mecanismo incompleto, cuja ativação depende de um sujeito leitor/ouvinte pronto para interagir com o sujeito autor/locutor, perfazendo e construindo os diversos caminhos semânticos da linguagem no processo de interpretação. É, pois, nesse sentido, que se pode reconhecer o texto como um objeto virtual e a leitura como um caminho semântico de atualização, trilhado por um sujeito-leitor consciente de seu papel de co-autor de um discurso, nível que faz da língua um contrato social (SILVA, 2005).

Em termos de potencialidade, pode haver em um texto diversos níveis de significados, ou seja, além de um sentido explícito, é possível encontrar-se toda uma gama de sentidos implícitos, ligados à intencionalidade de quem o escreveu. Nas palavras de Umberto Eco (1986, p. 36), "um texto distingue-se de outros tipos de expressão por sua maior complexidade". E o motivo dessa complexidade, sempre segundo o referido autor, é justamente o fato de um texto ser entremeado do "não-dito".

\section{Níveis de leitura}

Assim como existem níveis de significados em um texto, existem vários níveis de leitura ativa, dentre os quais se destacam três: a leitura exploratória, a analítica e a crítica (ADLER; DOREN, 1974). A leitura exploratória é aquela que se faz de maneira oblíqua quando se busca um máximo de informação num mínimo de tempo, com vistas à apreensão do teor global de um texto. Sua realiza-

2 Grifos da autora citada. ção permite levantar informações que conduzem à ideia central por meio dos seguintes procedimentos: rápida leitura do título, introdução e conclusão, sem perder de vista a distribuição gráfica do texto, o nome do autor, data e fonte de publicação, bem como outros segmentos em destaque. Concomitante a esses procedimentos de leitura inspecional, deve-se formular expectativas acerca do conteúdo, mediante a busca de pistas textuais que permitem aproximar respostas à pergunta: do que trata o texto como um todo?

Cabe, aqui, esclarecer que a leitura exploratória vai mais além de um simples mecanismo pertinente às denominadas 'leituras dinâmicas'. Isto, por duas razões. De um lado, porque se trata de um nível de leitura cujas estratégias demandam a interação deliberada do leitor com as ideias do autor. Nesse sentido, o leitor tem oportunidade de comparar as ideias contidas no texto com suas expectativas iniciais. De outro lado, porque a obtenção de um máximo de informações em tempo mínimo não constitui um fim em si mesmo, mas antes a continuidade de um processo metacognitivo. ${ }^{3}$ Essa continuidade encontra-se em consonância com as demais atividades mentais associadas aos níveis de leitura subsequentes, quais sejam, a leitura analítica e a leitura crítica.

A leitura analítica envolve um processo de decompor um todo em suas partes e, sobretudo, uma habilidade mental para identificar a ideia principal de cada unidade paragráfica e suas relações dentro do texto. O processo de análise de um texto exige a conjugação das atividades cognitivas de estruturação e de lógica. Enquanto a leitura exploratória favorece a compreensão do texto em sua globalidade, a leitura analítica permite, de modo particular, a apreensão do plano seguido pelo autor. Para tanto, há que se levar em conta, além das etapas observadas durante a leitura inspecional, o seguinte: um autor geralmente informa, explica, interpreta, discute e prediz. Mas pode também impressionar, emocionar e até mesmo seduzir durante o processo de leitura, como se poderá constatar mais adiante. A operação de decompor um todo em suas partes, num movimento de descontextualização e recontextualização de ideias, perpassa todo o processo de leitu-

3 O termo metacognitivo é, aqui, utilizado no sentido de controle consciente do conhecimento, em oposição a conhecimento automático ou inconsciente, conforme sugere Mary Kato (1987, p. 101-102). 
ra analítica como se fosse um mecanismo de radiografia. Na realidade, a identificação de qualquer estrutura implica encontrar os elementos concretos que a integram, bem como suas redes de conexão. No caso de uma estrutura textual, cuja rede enlaça elementos linguísticos e discursivos, dispostos respectivamente em termos de conectividade sequencial e conectividade conceptual, detectá-la equivale a abstrair, sobretudo, os elementos conceptuais que permitem radiografar semanticamente o texto.

A leitura crítica é um dos níveis de leitura em que o ato de ler pressupõe um senso acurado de julgamento, uma capacidade de analisar situações ou aspectos de uma realidade sem se deixar levar pelas primeiras impressões. Um leitor dotado de senso crítico é aquele que examina e, em condições propícias, avalia atentamente o teor de veracidade de um dado texto antes de aceitar as ideias ali veiculadas. Trata-se do leitor que é capaz de estabelecer conclusões acerca de ideologias subjacentes à intencionalidade do autor, bem como de se projetar sobre o texto, completando-o a partir de suas experiências de vida e de sua bagagem cultural.

A cada nova leitura crítica de um texto está ligada a perspectiva da descoberta de novos significados não detectados nas leituras anteriores, principalmente as significações dos subtendidos e pressupostos implícitos, ou seja, não manifestados na superfície linguística. Novas leituras implicam atitudes conscientes de busca, alimentadas pela curiosidade intelectual do leitor.

Sabe-se que um leitor se distingue de outro na medida de sua capacidade de se monitorar e, ao mesmo tempo, de se entregar durante o ato de leitura, o que poderá ser experimentado a seguir.

\section{Um convite para exercícios de leitura(s)}

Iniciemos a leitura do texto Rio acima, que foi produzido por um conhecido escritor, jornalista, humorista e cronista brasileiro.

\section{Rio acima}

Todos os rios levam ao mistério. Do Aar ao Zwetti. Do Orinoco ao Deseado, passando pelo Oiapoque e pelo Chuí. Do Negro ao Branco. Do Madeira ao Prata. Do Grande ao Chico. O das Antas, o das Velhas, o dos Macacos, o das Mortes. O rio da Vida, senhoras e senhores. Segurem-se até passarmos as pororocas. Aqui o Amazonas recebe as águas do seu maior afluente, o Atlântico. Aqui o Nilo muda de Nome e vira Mediterrâneo. Por essa boca o Mississipi expeliu Cuba, Porto Rico e todas as ilhas das Caraíbas. Aqui termina o Tejo e começa o mundo, uma obra de Camões. Aqui começa o nosso tour.

Rio acima. Observem como, de onde estamos, vemos passar as margens de ambos os lados...

Engano, somos nós que passamos. Protejam a cabeça do Sol e meditem sobre a finitude humana. Será servido um lanche antes de passarmos a fábrica de celulose, porque depois ninguém conseguirá comer. À esquerda, uma usina nuclear. Vejam os peixes fosforescentes. Vejam os banhistas fosforescentes. Não ponham a mão na água se não quiserem perdê-la. À direita, boiando, alguns mendigos. Prisioneiros de mãos amarradas. Vários fetos. Sapatos. Urinóis. Pneus. Sinais de civilização.
Uma nota pessoal, senhoras e senhores. Aquela casa na margem direita é minha. Tinha um coqueiro do lado que, coitado, de saudade já morreu, e o videoshop do outro lado, claro é novo. Aquela é a minha família, e aquele menino com água na cintura abanando para nós, sou eu. Mas isto também já passou. Rio acima!

O garoto abandonado naquele barco é Huckelbery Finn. Abanem, abanem. Aquela figura que acaba de mergulhar no rio do galho de uma árvore é Tarzan. Vejam como um jacaré se aproxima. Os dois se engalfinham. Não se preocupem, Tarzan vencerá.

Na margem direita, um lobo e um cordeiro conversando. Da margem esquerda, João Guimarães Rosa contempla a terceira margem. O bebê flutuando dentro da cesta é Moisés.

Estamos no Rubicão! Porcaria, pois não? Vocês notarão que muitos rios históricos não merecem o nome que têm. O Danúbio, veremos mais adiante, não é azul. O Vermelho é marrom. O Amarelo é cinzento. O Mekong é vermelho de tanto sangue. Rio acima. Estamos no Tâmisa. Agora no Avon. Aquele ali na margem, pensativo, é Shakespeare. Vejam, no meio do rio, rodeada de flores, mantida à tona pelas suas vestes 
infladas, a doce Ofélia. Abanem, abanem. Eu não disse que este tour tinha de tudo? Agora preparem suas câmeras. Ai vem, na sua barcaça imperial, Cleópatra descendo o Nilo. Rio acima. Estamos no Reno, no Pó, no Yang-tze, no São Francisco, no Tigre, no Eufrates, no Volga, no Jordão. Aquela cena vocês certamente vão querer fotografar, João Batista batizando Jesus. Estamos no Ganges, onde os vivos despejam os seus mortos e depois se lavam. O rio é sempre o mesmo. A água que purifica é a mesma que recebe o esgoto ácido. A água que mata a sede é a mesma que afoga, a que passa e a que não passa.

O rio é a Portela. À direita, Paulinho da Viola. Aquela cabecinha de nadador ali é a do Mao.
Galhos, troncos, casas, gado, canoas viradas, quatro com timão e sem timão - e uma fábrica inteira rebocada do Japão.

As águas começam a ficar lodosas. As grandes árvores se tocam sobre o rio. Estamos no Congo, a caminho do coração das trevas. Da fonte obscura de tudo. Mistash Kurtz, he dead. O cheiro azedo de limo e fósseis. $\mathrm{O}$ horror, o horror. $\mathrm{O}$ mar está longe, chegamos a nossa vertente. $\mathrm{E}$ a origem de tudo não é mistério, é um buraco no chão. Há outros rios debaixo destes, e é para lá que vamos um dia. Rio abaixo. A gorjeta é voluntária, obrigado.

VERÍSSIMO, Luis Fernando Revista VEJA, 29 de março de 1989
O texto acima, já de início, permite-nos chamar a atenção do leitor não só pelo complexo e, ao mesmo tempo, sugestivo tour histórico anunciado no primeiro parágrafo, mas também pela posição de Luis Fernando Veríssimo, em seu papel de escritor jornalista (ou jornalista escritor), em termos de sua contribuição a um suporte midiático, no caso, a Revista VEJA, edição 1073, ano 22, n 13, publicada em 29 de março de 1989. Cabe, aqui, esclarecer que as duas setas tipográficas foram acrescentadas, à margem do texto, somente para sinalizar os rumos básicos da leitura que demanda, por sua vez, uma série complexa de atos separados. Tais atos podem ser associados, conforme Silva (1997), aos seguintes tipos de atividades cognitivas:

atividade perceptiva, relacionada a uma capacidade rápida e precisa de busca de informações para a identificação do todo;

atividade visual-espacial, ligada simultaneamente à visão e ao espaço, sendo este último associado à ideia de lugar, superfície e distância;

atividade de estruturação, vinculada à identificação de estruturas de ideias e argumentos, a partir da observação de segmentos individuais, tais como palavras e expressões;

atividade lógica, mediante a identificação de conexões lógicas de ideias, ou de fatos históricos associados a seus respectivos contextos;

atividade verbal, pertinente à captação de uma palavra
As duas primeiras atividades elencadas acima são típicas da leitura exploratória, enquanto as seguintes concernem à leitura analítica. Voltemos em par, leitor/a, uma mirada empírica pela superfície do texto de Veríssimo.

Em termos de estruturação textual, podemos identificar o fluxo das ideias do autor, assim como sua apresentação de fatos históricos relativamente conhecidos seja em contextos situacionais próximos ou em contextos culturais distantes - materializado em unidades frasais e oracionais, em sua maioria, justapostas com predomínio de uma coordenação simples, paratática. Observa-se o saber gramatical atrelado à criatividade no uso da linguagem, cuja magnitude se evidencia na dimensão dialógica. Ressalte-se a intertextualidade, marcada pela presença constante de vozes de outros textos a guiarem, pela voz do autor, atitudes de reconhecimento dos interlocutores, ou melhor, participantes do "tour" tecido com engenho e arte, ainda que bem longe do estilo camoniano.

Pode-se afirmar que, antes mesmo de seduzir, o texto impressiona pela tessitura simples e, ao mesmo tempo, tão carregada de motivos para a aceitabilidade do leitor mais crítico que existe. Observe-se, ainda, que não há conectores lógicos de subordinação ao longo dos períodos enxutos que compõem cada parágrafo. Mas a conectividade conceptual (semântica) predomina e garante a tessitura do texto, o que confirma ser a coerência a propriedade mais relevante em um texto. Em poucas palavras, existem textos sem coesão, mas não existem textos sem coerência, propriedade que depende da (re)ação do 
interlocutor para atribuir sentido(s) a textos como este. A propósito, falta-nos mergulhar, ainda, em algumas das principais perguntas de quem se debruça em uma análise crítica.

Conforme sugere David Carraher (1987, p. 127):

a) O que está sendo afirmado?

b) Quais as principais questões envolvidas?

c) O que é usado para apoiar as ideias?

d) Que informações poderiam ajudar a esclarecer as questões principais?

Às perguntas destacadas acima, pode-se acrescentar a seguinte: qual é a ideologia presente no texto em análise? Em estudo recente (Silva, 2012, p. 17), pondero que "uma estrutura é ideológica na medida em que pode, ou não, corresponder à perspectiva do/a produtor/a ou do/a leitor/a". Considero pertinente evocar, aqui, as palavras de Guimarães (2009, p. 108), para quem “a ideologia define-se, portanto, como expressão de uma tomada de posição determinada, configurando-se, por isso, como condição essencial na relação mundo/linguagem”. Nessa perspectiva, vale chamar a atenção para o modo com que as informações são apresentadas ao longo do texto em questão. Ainda que despidas de um estilo argumentativo, as ideias são apresentadas revestidas de uma espécie de valor ou estatuto de verdade. Além disso, são ideias matizadas por um pendor atitudinal do autor, que envolve o leitor a partir de sua visão crítica do mundo.

Por outro lado, os temas tangenciados, ainda que de maneira literária, ao longo do texto - tais como problemas de poluição e agressão, respectivamente ao meio ambiente e ao ser humano - continuam ao lado de toda a beleza que ainda existe na história das águas quando navegamos rio acima, ou abaixo, através dos tempos. Além do mais, as questões enfocadas evocam o que sugere Freire (1981, p. 11-12): "linguagem e realidade se prendem de maneira dinâmica”.

Em poucas palavras, acabamos de assistir, agora em 2012, o encontro do "Rio + Vinte", evento que só vai acontecer outra vez daqui a vinte anos. Cabe, aqui, traçar um paralelo do texto examinado com a conferência das Nações Unidas, proferida recentemente em prol do desenvolvimento sustentável, em meio à presença de lideranças de inúmeras nações. Resulta que o meio ambiente, o ecossistema, a biodiversidade, a chuva ácida, o uso de energia suja - bem como a água que corre por todos os rios do planeta, antes de desembocar nos sete mares continuam a ser enfocados como tópicos que sinalizam, ora uma bandeira para ativistas, ora uma promessa de agenda de compromissos político-econômicos, diante dos apelos direcionados aos países ricos, que não querem repartir recursos que lhes sobram, ainda que tão cientes de questões complexas, tais como a pobreza do presente ou a escassez de água e de alimento no futuro próximo.

\section{Considerações finais}

Ao enfatizar a importância do ato de ler, Paulo Freire (1981, p. 20) afirma que "a leitura do mundo precede a leitura da palavra e a leitura desta implica a continuidade da leitura daquele". E vai mais longe. Além de esclarecer que a compreensão de um texto é alcançada mediante sua leitura crítica, através da qual se percebem as relações dentre o texto e o contexto, o educador brasileiro reitera sua proposta ao declarar que "a leitura da palavra não é apenas precedida pela leitura do mundo, mas por uma determinada forma de escrevê-lo, ou de reescrevê-lo", quer dizer, desdobrá-lo através de uma prática engajada de leitura.

Por outro lado, na esteira dos estudos críticos do discurso, comenta Fairclough (2001, p. 265) o seguinte:

é previsível que cada vez mais haja expectativa de que os analistas de discurso e os linguistas funcionem como tecnólogos do discurso ou tornem os resultados de suas pesquisas disponíveis a eles.

Que as reflexões aqui apresentadas possam significar uma pequena contribuição, em termos de incentivo, para todos aqueles/as que trabalham com textos, níveis de leitura, significados linguístico-discursivos, enfim, com a linguagem como prática social.

\section{Referências}

ADLER, M.; DOREN, C. van. A arte de ler. Tradução: José L. de Melo. Rio de Janeiro: Agir, 1974.

BEAUGRANDE, R.; DRESSLER, W. Introduction to text linguistics. London: Longman, 1981.

CARRAHER, D. Senso crítico: do dia-a dia às ciências humanas. São Paulo: Pioneira, 1983. 
ECO, H. Lector in fabula. São Paulo: Perspectiva, 1986.

FAIRCLOUGH, N. Discurso e mudança social. Brasília: Editora da UnB, 2001.

FREIRE, P. A importância do ato de ler. São Paulo: Cortez, 1989.

GUIMARÃES, E. Texto, discurso e ensino. São Paulo: Contexto, 2009.

HALLIDAY, M. A. K.; HASAN, R. Cohesion in English: english language. London: Longman, 1976.

KATO, M. No mundo da escrita: uma perspectiva psicolinguística. São Paulo: Ática, 1987.

KOCH, I.V.; TRAVAGLIA, L.C. Texto e coerência. São Paulo: Cortez, 1989.

KOCH, I.V. Desvendando os segredos do texto. São Paulo: Cortez, 2002.

KOCH, I.V. O texto e a construção de sentidos. São Paulo: Contexto, 1997.

LEVY, P. O que é virtual? Tradução: P. Neves. São Paulo: Editora 34, 1996.

MARCUSCHI, L.A. Produção textual, análise de gêneros e compreensão. São Paulo: Parábola Editorial, 2008.
ORLANDI, E. Interpretação: autoria, leitura e efeitos do trabalho simbólico. Petrópolis: Vozes, 1996.

RICOEUR, P. Preface. In: REAGAN, C. (Ed.). Studies in the Philosofy of Paul Ricoeur. Athens, Ohio: Ohio University Press, 1984.

SILVA, D.E.G. Da leitura do mundo à leitura da palavra. In: VI Simpósio de Língua e Literatura do UniCEUB - leitura: discurso, literatura e educação. Brasília: UniCEUB, 2008.

SILVA, D.E.G. Discurso e gramática: motivações cognitivas e interacionais. In: SILVA, D.E.G. (Org.). Nas instâncias do discurso: uma permeabilidade de fronteiras. Brasília: Editora da UnB, 2005.

SILVA, D.E.G. Estudos críticos do discurso no contexto brasileiro: por uma rede de transdisciplinaridade. Revista online de Literatura e Linguística, Recife, ano 5, n. 9, p. 224243. 2012. Disponível em: <http://www.revistaeutomia. com.br>. Acesso em: $11 \mathrm{dez} .2012$

SILVA, D.E.G. Produção de leitura, texto e textualidade: curso de extensão. In: IV Fórum Permanente de Professores. Brasília: Universidade de Brasília/CESPE, 1997.

VERÍSSIMO, Luís Fernando. Rio acima. Revista Veja, São Paulo, ano 22, n. 13, p. 53, 29 mar. 1989. 